\title{
Clinical Reasoning: A 29-Year-Old Man With Fevers and Rapidly Progressive Cranial Neuropathies
}

Alexa Dessy, MD, Stephen Berger, MD, PhD, Arooshi Kumar, MD, Scott N. Grossman, MD, Myrna Cardiel, MD, and Steven L. Galetta, MD

Neurology ${ }^{\circledR}$ 2021;97:95-98. doi:10.1212/WNL.0000000000012085

\section{Section 1}

A 29-year-old man with no prior known medical diagnoses presented to the emergency department with 5 days of fevers, chills, vomiting, headache, and neck pain followed by voice changes, difficulty swallowing, and intractable hiccups. The patient denied vision changes, weakness, numbness, recent travel, new medications, or illicit drug use. He had no personal or family history of neurologic illness. On questioning concerning possible toxic exposure, he noted recent consumption of sushi and raw meat at a restaurant; a friend who had eaten with him also experienced gastrointestinal illness after that meal.

On examination, the patient was diaphoretic with a temperature of $39.4^{\circ} \mathrm{C}$. He had nystagmus with left-beat in left gaze, right-beat in right gaze, and downbeat in the primary position. Ocular motility was full. Facial sensation was decreased in the left V2 and V3 distributions. There was subtle flattening of the right nasolabial fold. His speech was hoarse, dysphonic, and highpitched. The uvula deviated to the right on palate elevation testing. There was subtle pronation in the left upper extremity. Sensation to light touch was decreased in the left extremities in a nondermatomal pattern. He leaned towards the right on Romberg testing. His gait was widebased and unsteady.

\section{Questions for Consideration:}

1. How do the examination findings localize the lesion?

2. What is the differential diagnosis?

3. What are the next steps in evaluation?
Correspondence

Dr. Dessy

amdessy@gmail.com

GO TO SECTION 2 


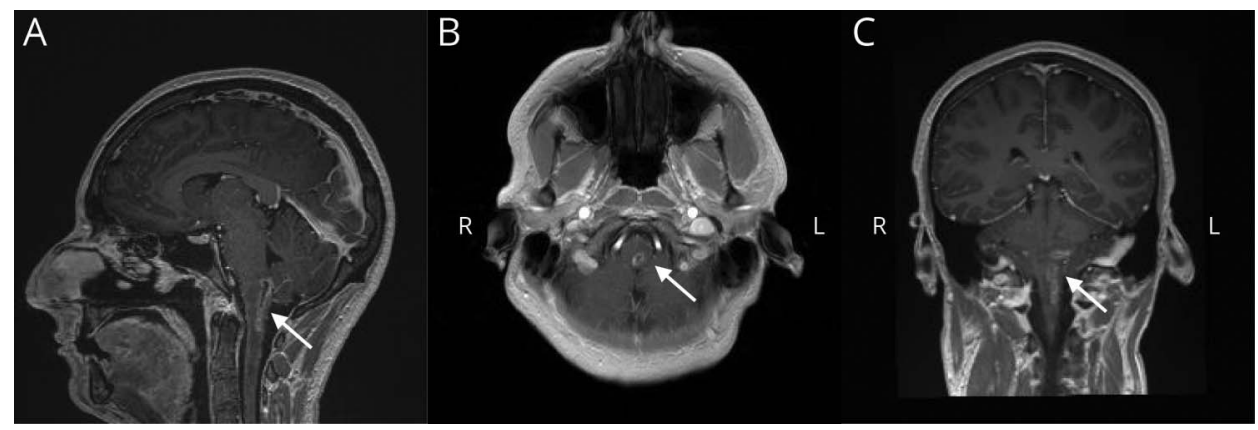

(A) Sagittal multiplanar reconstructed T1, gradient echo (MPR) demonstrating serpiginous medullary lesion extending into cervical cord (B). Axial T1 post-contrast demonstrating contrast enhancement in left medulla (C) Coronal MPR completing visual 3D depiction of longitudinal lesion.

\section{Section 2}

This constellation of multiple cranial nerve deficits, including trigeminal, facial, glossopharyngeal, and vagus impairment, with unilateral weakness and vestibulo-cerebellar involvement, localizes to the brainstem (lower midbrain to medulla, predominantly on the left side based on the cranial nerve palsies). The direction-changing nystagmus suggested involvement of tonic cells responsible for gaze-holding including the nucleus prepositus hypoglossi and medial vestibular nucleus in the medulla. The downbeat nystagmus localized to the cervicomedullary junction, resulting from imbalance of the semicircular canals favoring the anterior canal. Ipsilateral arm weakness suggested cruciate hemiplegia resulting from involvement of crossed lateral corticospinal fibers in the caudal medulla or injury to the anterior corticospinal tracts which travel ipsilateral. The differential diagnosis was broad, with initial emphasis on infectious etiologies, including common causes of bacterial meningoencephalitis in adults (e.g., Streptococcus and Neisseria), legionella, mycoplasma, Listeria, Lyme, syphilis, tuberculosis, and herpes simplex virus encephalitis.

Initial noncontrast head $\mathrm{CT}$ was normal. Neck $\mathrm{CT}$ with contrast suggested left vocal cord paralysis; ear, nose, and throat evaluation confirmed complete immobility of the left true vocal cord. Lumbar puncture initially revealed 460 nucleated cells with a lymphocytic predominance (79\%), protein $68 \mathrm{mg} / \mathrm{dL}$, and glucose $72 \mathrm{mg} / \mathrm{dL}$. The meningitis-encephalitis PCR panel was negative, as were bacterial and fungal cultures. MRI of the brain and cervical spine with and without contrast revealed an expansile, serpiginous, rim-enhancing lesion in the left dorsal medulla extending inferiorly to the level of $\mathrm{C} 2-\mathrm{C} 3$ (figure).

While undergoing evaluation, the patient's symptoms progressed. Small angle esotropia was noted, suggesting a mild sixth nerve palsy. He reported new oblique binocular diplopia, which improved with left head tilt and a monocular patch. There was a left hypertropia worse in left gaze consistent with skew deviation in a pattern commonly observed with downbeat nystagmus and cervicomedullary lesions. Right facial weakness worsened to a complete lower motor neuron pattern, corresponding to extension of the lesion to the right facial colliculus on repeat imaging. His voice became notably more dysphonic. The left upper extremity had more pronounced drift and confrontation testing revealed $4 / 5$ strength. There was leftsided dysmetria on finger to nose testing. The patient's respiratory status subsequently deteriorated, requiring intubation for acute hypoxic respiratory failure. On subsequent examinations, he had preserved upgaze and downgaze, but now had impaired horizontal gaze in both directions.

\section{Questions for Consideration:}

1. How do the new findings modify the differential?

2. What further workup is required?

3. What are the most important next steps in management?

\section{GO TO SECTION 3}




\section{Section 3}

Rapid symptom progression over the course of days suggested neoplasm or pathogens such as Coccidioides, Aspergillus, and neurocysticercosis were less likely. With no identified pathogen and CSF studies indicating a lymphocytic process, the differential diagnosis was broadened to include autoimmune and inflammatory processes. Neuromyelitis optica or antimyelin oligodendrocyte glycoprotein (MOG) disease were high on the differential given primary brainstem involvement, but aquaporin-4 receptor and MOG antibodies resulted negative. Other considerations included vasculitis (e.g., Behçet disease), neurosarcoidosis, or a paraneoplastic process.

Broad-spectrum antibiotics, vancomycin $15 \mathrm{mg} / \mathrm{kg} \mathrm{q} 8 \mathrm{~h}$ and ceftriaxone $2 \mathrm{~g} \mathrm{q1} \mathrm{h}$, had been started for empiric treatment of bacterial meningitis in the emergency department. Extensive workup was negative, including HIV antigen and antibody, immunoglobulin levels, titers for standard vaccinations, and complement levels. Additional serum laboratory studies were all negative, including blood cultures, Lyme disease, Cryptococcus, Aspergillus, syphilis, tuberculosis, histoplasma, $\beta$-D-glucan, antinuclear antibody, myeloperoxidase antibody, proteinase 3 , angiotensin-converting enzyme, serum protein electrophoresis, and immunofixation.

Given the clinical deterioration, the decision was made to repeat a lumbar puncture on day 5 . On this second set of CSF studies, Listeria monocytogenes was detected on the meningitisencephalitis PCR panel. All empiric antibiotics and antifungals that had been initiated were discontinued with the exception of meropenem $2 \mathrm{~g} q 8 \mathrm{~h}$. Ampicillin $2 \mathrm{~g} \mathrm{q} 4 \mathrm{~h}$ and gentamicin $1.7 \mathrm{mg} /$ $\mathrm{kg}$ q8h were started for synergistic treatment of Listeria rhombencephalitis. Notably, a single blood culture during this period returned positive for Listeria, suggestive of transient bacteremia. Serial MRI studies revealed T2/fluid-attenuated inversion recovery abnormalities consistent with worsening perilesional edema, prompting the addition of corticosteroids. Abscess drainage or surgical decompression were considered but ultimately not pursued after risk-benefit consideration. Meropenem was later changed to trimethoprim-sulfamethoxazole for a prolonged course. On follow-up examination 5 months after the initial presentation, the patient's horizontal gaze deficits had improved but he was still esotropic. Nystagmus was also less prominent in right and left gaze. Weakness and sensory loss persisted on the left side. He ambulated with a walker. Extensive physical therapy during the next 3 months allowed him to walk independently, but the esotropia persisted, for which botulinum toxin was injected into both medial recti to prevent contracture.

\section{Discussion}

Our patient likely acquired Listeria as a foodborne illness. He presented with several key examination features that localized to the lesion in the left dorsal medulla seen on imaging, including downbeat nystagmus, skew deviation, and intractable hiccups. Notably, the ipsilateral arm weakness likely represents cruciate hemiparesis, a rare neurologic manifestation that also localizes to the caudal medulla due to crossed lateral corticospinal tract fibers at that level or ipsilateral anterior corticospinal tracts.

Approaching the differential diagnosis from the perspective of neuroanatomic localization, a review of 34 cases of isolated medullary lesions from nonstroke causes identified neoplasms as the most common pathology observed (47\%), whereas infections were among the least common (3\%). ${ }^{1}$ The remainder were largely attributable to vascular malformations (15\%) and demyelinating or inflammatory lesions, including Sjögren, sarcoidosis, and Behçet (15\%). ${ }^{1}$ Interestingly, none of the patients with isolated medullary lesions were immunocompromised. Listeria is the most common cause of infectious rhombencephalitis and tends to affect immunocompetent individuals. Other common infectious etiologies for medullary lesions include tuberculomas and toxoplasmosis, particularly when ring enhancement or nodularity is present. Listeria rhombencephalitis appears to be an infrequent manifestation of neurolisteriosis overall, as brainstem involvement was identified in only $10 \%$ of cases in one imaging series. ${ }^{2}$ More classically, Listeria meningoencephalitis is observed in neonates or pregnant or elderly patients and arises either sporadically or from food outbreaks. When Listeria is suspected, ampicillin $2 \mathrm{~g}$ IV q4h should be initiated empirically. Once the diagnosis is confirmed, preferred treatment includes ampicillin or penicillin, combined with gentamicin.

Our case demonstrates the typical biphasic pattern seen in Listeria rhombencephalitis, including a prodrome of 4-5 days followed by rapid evolution of neurologic symptoms. In a review of 62 cases of Listeria rhombencephalitis, isolated cranial nerve palsies were the initial presenting neurologic sign in almost half of the cases. ${ }^{3}$ However, with disease progression, up to $80 \%$ of cases involved hemiparesis, hemisensory loss, or cerebellar signs in addition to cranial nerve deficits. As in our patient, pontomedullary-localizing clinical signs and symptoms were frequent, including dysphagia, dysphonia, dysarthria, facial weakness, and vertigo. Asymmetry in the neurologic manifestations was also common, as in our case.

Listeria rhombencephalitis can be challenging to recognize, as the clinical and imaging characteristics may mimic other disease entities. The broad differential may engender initial misdiagnosis and treatment delay. Case reports commonly describe ring-enhancing abscesses with a serpiginous ("wormlike" or "tubular") appearance with surrounding edema., Definitive diagnosis requires confirmation of the pathogen in CSF testing. However, initial CSF studies can be normal or nonspecific, as was the case in our patient. Among the 62 cases, lymphocytic predominance in the CSF was noted in only $58 \%$. Initial cultures identified Listeria in $33 \%$ of cases, and repetition of cultures improved the yield to $41 \% .^{3}$ Therefore, even in the absence of compelling CSF studies or imaging, it is important to maintain a high index of suspicion based on the clinical scenario, particularly because early 
treatment with antibiotics can mitigate the high morbidity and mortality associated with this disease. With appropriate initial treatment, the reported survival rate of patients with Listeria rhombencephalitis is greater than $70 \% .^{3}$ However, as in our case, long-term neurologic sequelae are common in patients who have survived treatment.

\section{Study Funding}

The authors report no targeted funding.

\section{Disclosure}

The authors report no disclosures relevant to the manuscript. Go to Neurology.org/N for full disclosures.

\section{Appendix Authors}

\begin{tabular}{lll}
\hline Name & Location & Contribution \\
\hline Alexa Dessy, MD & $\begin{array}{l}\text { NYU Langone Health, } \\
\text { New York }\end{array}$ & $\begin{array}{l}\text { Drafting and revising } \\
\text { manuscript }\end{array}$ \\
\hline $\begin{array}{l}\text { Stephen Berger, } \\
\text { MD, PhD }\end{array}$ & NYU Langone Health, & Drafting manuscript \\
\hline
\end{tabular}

Appendix (continued)

\begin{tabular}{lll}
\hline Name & Location & Contribution \\
\hline Arooshi Kumar, MD & $\begin{array}{l}\text { NYU Langone Health, } \\
\text { New York }\end{array}$ & $\begin{array}{l}\text { Drafting manuscript, } \\
\text { figure design }\end{array}$ \\
\hline $\begin{array}{l}\text { Scott N. Grossman, } \\
\text { MD }\end{array}$ & $\begin{array}{l}\text { NYU Langone Health, } \\
\text { New York }\end{array}$ & $\begin{array}{l}\text { Drafting and revising } \\
\text { manuscript }\end{array}$ \\
\hline Myrna Cardiel, MD & $\begin{array}{l}\text { NYU Langone Health, } \\
\text { New York }\end{array}$ & Revising manuscript \\
\hline $\begin{array}{l}\text { Steven L. Galetta, } \\
\text { MD }\end{array}$ & $\begin{array}{l}\text { NYU Langone Health, } \\
\text { New York }\end{array}$ & Revising manuscript \\
\hline
\end{tabular}

\section{References}

1. Prakkamakul S, Schaefer P, Gonzalez G, Rapalino O. MRI patterns of isolated lesions in the medulla oblongata. J Neuroimaging. 2017;27(1):135-143.

2. Charlier C, Poirée S, Delavaud C, et al. Imaging of human neurolisteriosis: a prospective study of 71 cases. Clin Infect Dis. 2018;67(9):1419-1426.

3. Armstrong RW, Fung PC. Brainstem encephalitis (rhombencephalitis) due to Listeria monocytogenes: case report and review. Clin Infect Dis. 1993;16(5):689-702.

4. O'Callaghan M, Mok T, Lefter S, Harrington H. Clues to diagnosing culture negative Listeria rhombencephalitis. BMJ Case Rep. 2012;2012:bcr2012006797.

5. Slezák S, Žižka J, Kvasnička T, et al. Worm-like appearance of Listeria monocytogenes brain abscess: presentation of three cases. Neuroradiology. 2020;62(9):1189-1193.

\section{Online Learning for Everyone}

No matter your career stage, interest, or learning style, the AAN has a wide variety of convenient online CME, self-assessment, and other learning activities to suit your needs. From bite-sized learning opportunities to self-assessment programs, help preparing you for the boards or continuing certification, or on-demand access to popular AAN conferences, the AAN has you covered. Visit AAN.com/Learn today.

\section{Disputes \& Debates: Rapid Online Correspondence}

The editors encourage comments on recent articles through Disputes \& Debates:

Access an article at Neurology.org/N and click on "MAKE COMMENT" beneath the article header.

Before submitting a comment to Disputes \& Debates, remember the following:

- Disputes \& Debates is restricted to comments about articles published in Neurology within 6 months of issue date

- $\quad$ Read previously posted comments; redundant comments will not be posted

- Your submission must be 200 words or less and have a maximum of 5 references; the first reference must be the article on which you are commenting

- You can include a maximum of 5 authors (including yourself) 


\section{Neurology}

\section{Clinical Reasoning: A 29-Year-Old Man With Fevers and Rapidly Progressive Cranial Neuropathies}

Alexa Dessy, Stephen Berger, Arooshi Kumar, et al.

Neurology 2021;97;95-98 Published Online before print April 23, 2021

DOI 10.1212/WNL.0000000000012085

\section{This information is current as of April 23, 2021}

\section{Updated Information \&} Services

\section{References}

Subspecialty Collections

\section{Permissions \& Licensing}

Reprints including high resolution figures, can be found at: http://n.neurology.org/content/97/2/95.full

This article cites 5 articles, 1 of which you can access for free at: http://n.neurology.org/content/97/2/95.full\#ref-list-1

This article, along with others on similar topics, appears in the following collection(s):

\section{Abscess}

http://n.neurology.org/cgi/collection/abscess

All Infections

http://n.neurology.org/cgi/collection/all_infections

Bacterial infections

http://n.neurology.org/cgi/collection/bacterial_infections

Clinical neurology examination

http://n.neurology.org/cgi/collection/clinical_neurology_examination

Clinical neurology history

http://n.neurology.org/cgi/collection/clinical_neurology_history

Information about reproducing this article in parts (figures,tables) or in its entirety can be found online at:

http://www.neurology.org/about/about_the_journal\#permissions

Information about ordering reprints can be found online:

http://n.neurology.org/subscribers/advertise

Neurology ${ }^{\circledR}$ is the official journal of the American Academy of Neurology. Published continuously since 1951, it is now a weekly with 48 issues per year. Copyright (C 2021 American Academy of Neurology. All rights reserved. Print ISSN: 0028-3878. Online ISSN: 1526-632X.

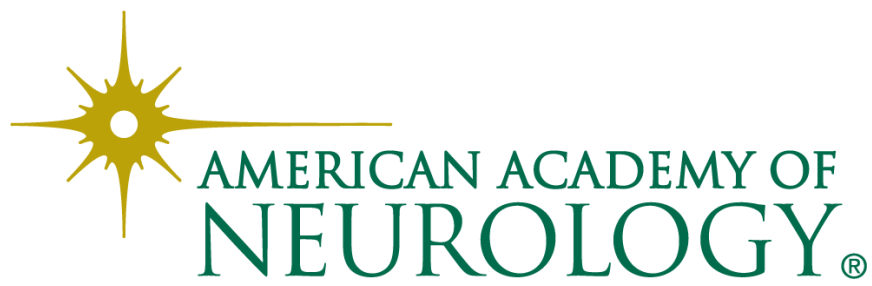

